\title{
Glycaemic index and glycaemic load values of cereal products and weight-management meals available in the UK
}

\author{
C. Jeya K. Henry*, Helen J. Lightowler, Lis M. Dodwell and Jacqueline M. Wynne \\ Nutrition and Food Science Group, School of Life Sciences, Oxford Brookes University, Gipsy Lane Campus, Headington, Oxford \\ OX3 OBP, UK
}

(Received 20 June 2006 - Revised 12 January 2007 - Accepted 12 January 2007)

\begin{abstract}
There is currently an increased global interest in the published glycaemic index (GI) values of foods. The aim of the present work was to supplement a previous study on the glycaemic response of 140 foods available in the UK by studying a further forty-four foods. One hundred and twenty-two healthy subjects, with a mean age of 32.4 (SD 11.4) years and a mean BMI of 23.6 (SD 3.6 ) $\mathrm{kg} / \mathrm{m}^{2}$, were recruited to the study. Subjects were served equivalent available carbohydrate amounts $(50 \mathrm{or} 30 \mathrm{~g})$ of test foods (cereal products and weight-management meals) and a standard food (glucose) on separate occasions. Capillary blood glucose was measured from finger-prick samples in fasted subjects $(0 \mathrm{~min})$ and at 15, 30, 45, 60, 90 and $120 \mathrm{~min}$ after starting to eat each test food. For each test food, the GI value was determined, and the glycaemic load was calculated as the product of the GI and the amount of available carbohydrate in a reference serving size. The GI values of the foods tested ranged from 23 to 83. Of the forty-four foods tested, thirty-three were classified as low-GI, eight as medium-GI and three as high-GI foods. Most GI values of the foods tested compared well with previously published values for similar foods. In summary, this study provides reliable GI and glycaemic load values for a range of foods, further advancing our understanding of the glycaemic response of different foods. The data reported here make an important addition to published GI values.
\end{abstract}

Glycaemic index: Glycaemic load: Cereal products: Weight-management meals

The glycaemic index (GI), first introduced by Jenkins and colleagues (1981), is a classification of the blood glucose-raising potential of carbohydrate foods. It is defined as the incremental area under the blood glucose curve of a $50 \mathrm{~g}$ carbohydrate portion of a test food expressed as a percentage of the response to $50 \mathrm{~g}$ carbohydrate of a reference food taken by the same subject, on a different day (FAO/WHO, 1998). The principle is that the slower the rate of carbohydrate absorption, the lower the rise in blood glucose level and the lower the GI value (Augustin et al. 2002). Indeed, high-GI foods are characterised by fast-release carbohydrate and higher blood glucose levels. A GI value of 70 or more is considered high, one of 56-69 is medium and one of 55 or less is low (where glucose $=100$; Brand-Miller et al. 2003).

Since the concept of GI was first introduced, many studies have investigated the potential health benefits of low-GI foods. Recent data support the preventive potential of a low-GI diet against the development of type 2 diabetes and cardiovascular disease (Salmeron et al. 1997a,b; Frost et al. 1999). There is also an interest in the potential of low-GI diets for bodyweight management. Several studies have shown that low-GI foods, or lowering the GI of a food, reduces hunger and results in a lower energy intake (Ludwig, 2000; Warren et al. 2003).

GI values represent the glycaemic response of equivalent available carbohydrate amounts of foods and are therefore not always representative of the glycaemic effect of a typical serving of that food. To quantify the overall glycaemic effect of a standard portion of food, the concept of glycaemic load (GL) was introduced (Salmeron et al. 1997a,b). This is the product of the amount of available carbohydrate in that serving and the GI of the food divided by 100 . It is often necessary to consider the GL alongside GI values, especially when the carbohydrate content of the food is relatively small. A GL value of 10 or less is considered low, a GL value of $11-19$ is medium and one of 20 or more is high (BrandMiller et al. 2003).

Carbohydrate foods consumed in equivalent available carbohydrate amounts produce different glycaemic responses depending on many factors, such as particle size, cooking and food processing, other food components (e.g. fat, protein, dietary fibre), the proportion and type of sugars and starch, and the starch structure (Björck et al. 1994). Consequently, there is often considerable variation in the GI of the same food produced in different countries or by different manufacturers. The publication of reliably measured GI and GL values is needed to facilitate consumer application and to reduce unnecessary regional duplication. Until recently, the vast majority of published GI values have been Australasian or Canadian (Foster-Powell et al. 2002). Henry et al. (2005) published a paper detailing GI and GL values for 140 foods

Abbreviations: GI, glycaemic index; GL, glycaemic load; IAUC, incremental area under the blood glucose response curve.

* Corresponding author: Professor C. J. K. Henry, fax +44 (0) 1865 483618, email jhenry@ brookes.ac.uk 
commonly consumed in the UK. Thus, the aim of the current work was to provide additional GI and GL values for a wider range of foods available in the UK.

\section{Methods}

\section{Subjects}

One hundred and twenty-two healthy subjects, with a mean age of 32.4 (SD 11.4) years and a mean BMI of 23.6 (SD $3.6) \mathrm{kg} / \mathrm{m}^{2}$, were recruited via posters distributed throughout Oxford Brookes University, in addition to announcements in lectures and through personal networks. Exclusion criteria were as follows: age less than 18 or over 60 years, a BMI of $27 \mathrm{~kg} / \mathrm{m}^{2}$ or more, and a fasting blood glucose value of over $6 \cdot 1 \mathrm{mmol} / \mathrm{l}$. Ethical approval for the study was obtained from the University's Research Ethics Committee. Subjects were given full details of the study protocol and had the opportunity to ask questions. All subjects gave written informed consent prior to participation.

\section{Study protocol}

The protocol used was adapted from that described by Wolever et al. (1991) and is in line with procedures recommended by the FAO/WHO (1998). The FAO/WHO state that, to determine the GI of a food, tests should be repeated on six or more subjects; thus in the current study, each product was tested on a minimum of ten subjects. Overall, subjects tested between one and twelve different foods during the study. On the day prior to a test, subjects were asked to restrict their intake of alcohol and caffeine-containing drinks and to restrict their participation in intense physical activity. Subjects were also told not to eat or drink after 21.00 hours on the night before a test, although water was allowed in moderation.

\section{Test foods}

Forty-four different foods were tested, including breads, breakfast cereals, mixed meals (breakfast cereals with milk), snack bars and weight-management meals, representing a diverse range of foods commonly consumed in the UK. All foods were tested in equivalent available carbohydrate amounts (50 or $30 \mathrm{~g}$ ) and compared with a reference food (glucose). In the case of foods with a low to moderate carbohydrate density, it is justified to reduce the carbohydrate load to avoid an unrealistically large meal size; such reductions are shown to produce similar GI values (Brouns et al. 2005). For each food product, the experimental portion was determined using data for available carbohydrate provided by the relevant food manufacturer. In the case of the mixed meals, both the breakfast cereals and milk contributed to the $50 \mathrm{~g}$ available carbohydrate (Table 1 ).

In accordance with FAO/WHO recommendations, subjects tested each test food once and the reference food three times randomly on separate days, with a gap of at least $1 \mathrm{~d}$ between measurements to minimise carry-over effects (FAO/WHO, 1998). Subjects were studied in the morning after a $12 \mathrm{~h}$ overnight fast. Subjects consumed the reference food/test product within $15 \mathrm{~min}$. The test products and the reference food
Table 1. Amount of available carbohydrate from mixed meals

\begin{tabular}{|c|c|c|}
\hline \multirow[b]{2}{*}{ Food } & \multicolumn{2}{|c|}{$\begin{array}{c}\text { Amount of available carbo- } \\
\text { hydrate }(\mathrm{g})\end{array}$} \\
\hline & Test food & Milk \\
\hline Cereal biscuit & $40 \cdot 6$ & $9 \cdot 4$ \\
\hline Cereal biscuits - cocoa flavour & $40 \cdot 6$ & $9 \cdot 4$ \\
\hline Cereal biscuits - honey flavour & $40 \cdot 7$ & $9 \cdot 3$ \\
\hline Cereal biscuits - fruit flavour & $40 \cdot 4$ & $9 \cdot 6$ \\
\hline Cereal flakes with fruit & 41.9 & $8 \cdot 1$ \\
\hline Cocoa crunch cereal & $39 \cdot 6$ & $10 \cdot 4$ \\
\hline Honey crunch cereal & $40 \cdot 3$ & $9 \cdot 7$ \\
\hline Hot oat cereal I & $37 \cdot 7$ & $12 \cdot 3$ \\
\hline Hot oat cereal II & $35 \cdot 6$ & $14 \cdot 4$ \\
\hline Hot oat cereal - berry flavour & $41 \cdot 0$ & $9 \cdot 0$ \\
\hline Hot oat cereal - cocoa flavour & $37 \cdot 3$ & $12 \cdot 7$ \\
\hline Hot oat cereal - fruit flavour & $38 \cdot 2$ & $11 \cdot 8$ \\
\hline Hot oat cereal - honey flavour & $40 \cdot 9$ & $9 \cdot 1$ \\
\hline Hot oat cereal - orchard fruit & $40 \cdot 6$ & $9 \cdot 4$ \\
\hline
\end{tabular}

were served with $200 \mathrm{ml}$ water, and a further $200 \mathrm{ml}$ water were given during the subsequent $2 \mathrm{~h}$. Subjects remained sedentary during each session.

\section{Blood glucose measurements}

A fasting blood sample was taken at $0 \mathrm{~min}$, and the reference food/test product was consumed immediately after this. Further blood samples were taken at 15, 30, 45, 60, 90 and $120 \mathrm{~min}$ after starting to eat. Blood was obtained by fingerprick using the Unistik 2 single-use lancing device (Owen Mumford). Prior to a finger-prick, subjects were encouraged to warm their hand to increase blood flow. Fingers were not squeezed to extract blood from the fingertip, in order to minimise plasma dilution. Blood glucose was measured using Ascensia Contour automatic blood glucose meters (Bayer HealthCare). The blood glucose meters were calibrated daily using control solutions from the manufacturer, and were also regularly calibrated against a clinical dry chemistry analyser (Reflotron Plus; Roche) and the HemoCue Glucose $201+$ analyser (HemoCue Ltd).

Figure 1 shows the Pearson regression and Bland-Altman analyses for a random selection of 1400 blood samples simultaneously measured using the Ascensia Contour and the HemoCue Glucose $201+$ analyser. There was a very strong correlation $(r=0.960, P<0.001)$ and good agreement (mean difference $0.10 \mathrm{mmol} ; 95 \%$ CI $0 \cdot 07,0 \cdot 12$; limits of agreement 0.88 and 1.08 ) between blood glucose measurements using the automatic analyser and the HemoCue analyser.

\section{Calculation of glycaemic index and glycaemic load}

The incremental area under the blood glucose response curve (IAUC), ignoring the area beneath the baseline, was calculated geometrically for each food (FAO/WHO, 1998). The IAUC for each test product eaten by each subject was expressed as a percentage of the mean IAUC for the reference food eaten by the same subject:

$$
\mathrm{GI}=(\mathrm{IAUC} \text { test product/IAUC reference food }) \times 100 \text {. }
$$



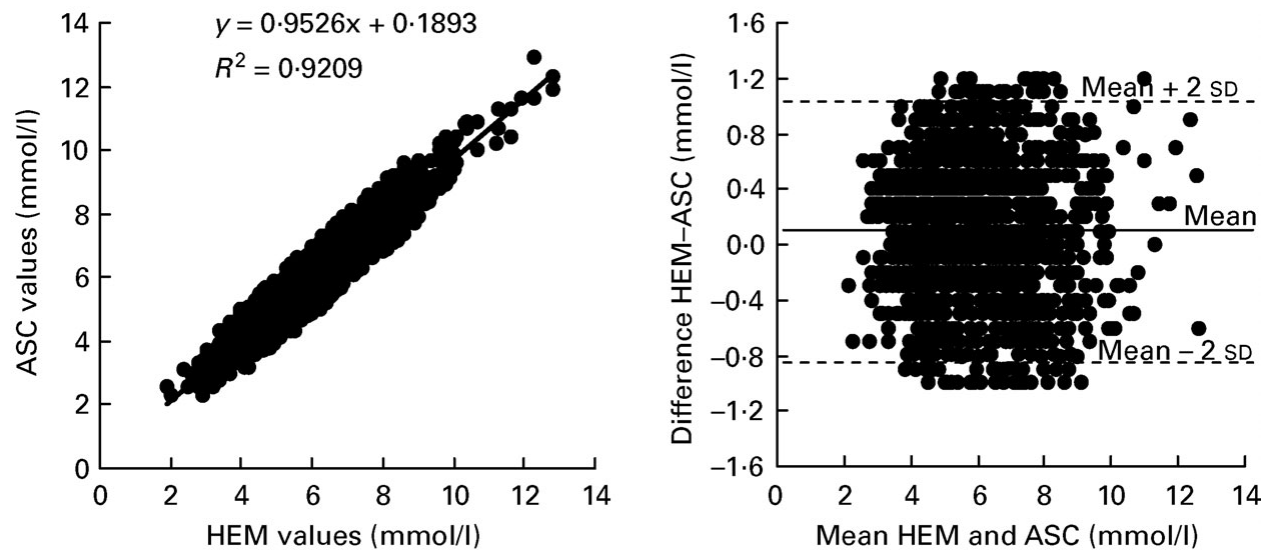

Fig. 1. Pearson regression and Bland-Altman analyses of 1400 random blood glucose measurements between the Ascensia Contour (ASC) and the HemoCue $201+$ analyser (HEM).

The GI of each test product was taken as the mean for the whole group.

The GL of a specific serving of each food was calculated using the following equation:

$$
\begin{aligned}
\mathrm{GL}= & (\text { GItest food } \\
& \times \text { weight of availablecarbohydrate } \text { inaserving of testfood }[\mathrm{g}]) / 100 .
\end{aligned}
$$

The serving size of each food was taken from manufacturers' information or, when this was not available, from standard food portion sizes (Food Standards Agency, 2004).

\section{Statistical analysis}

Statistical analysis was performed using the Statistical Product and Service Solutions software (SPSS version 11.0.1; SPSS Inc., Chicago, IL, USA). To examine the correlation and agreement between the automatic analyser and the HemoCue Glucose $201+$ analyser, Pearson's correlation coefficient and the method of Bland \& Altman (1986) were used. Pearson's correlation coefficient and Spearman's correlation coefficient (rho) were used, where appropriate, to assess the relationship between the GI values and macronutrient content of the test foods. Statistical significance was set at $P<0.05$.

\section{Results}

The GI and GL values for all forty-four tested foods are given in Table 2. Values are given as means with their standard errors. The GI values of the foods tested ranged from 23 (chocolate flavour drink) to 83 (hot oat cereal with water). Of the forty-four foods tested, thirty-three were classified as low-GI, eight as medium-GI and three as high-GI foods. The GL per serving ranged from $2 \cdot 3$ (choice grain crackers, rich tea biscuits) to $20 \cdot 9$ (chocolate soya drink).

Bread and crackers and breakfast cereals represented a wide range of GI values, most showing low (e.g. multiseed bread, choice grain crackers, high-fibre cereals), with some medium (e.g. rye crackers, cereal flakes with fruit) and two high (e.g. cereal biscuit, hot oat cereal I with water), values. All snack bars and sweet biscuits fell into the low-GI category. Most weight-management meal products fell into the low-GI category, with the exception of the chocolate soya drink (high), and vegetable and chicken, and mushroom soups (medium).

The addition of semi-skimmed milk to the breakfast cereals reduced the GI values from a high to a low classification. The GI values of cereal biscuits and hot oat cereal I were reduced from 72 to $47(P=0 \cdot 112)$ and 83 to $47(P=0 \cdot 011)$, respectively, when consumed with milk.

There was no relationship between the GI value and the amount of protein per $50 \mathrm{~g}$ available carbohydrate portion (Fig. 2; Pearson's $r=-0.288 ; P=0.061$ ). There was, however, a weak negative relationship between the GI value and amount of fat per experimental portion (Fig. 2; Spearman's rho $=-0.373 ; P=0.014)$. When the weight-management meals (i.e. lower-fat products) were excluded, there was a strong negative relationship between GI value and amount of fat per experimental portion (Fig. 3; Spearman's rho $=-0.727 ; P<0.001)$, but not between GI value and amount of protein per $50 \mathrm{~g}$ available carbohydrate portion (Fig. 3; Pearson's $r=-0.295 ; P=0 \cdot 095$ ).

\section{Discussion}

This study provides the GI values of a number of foods not previously tested, further expanding our database of the glycaemic response of different foods available in the UK. The GI values of several foods and mixed meals reported in this study have not previously been published. Where, however, comparison with published values (Foster-Powell et al. 2002) was possible, foods tested in the current study compared favourably. For example, in healthy subjects, the GI values for wheat biscuits (61-75), rye crisp bread (69), meal-replacement bars (30-45) and meal-replacement chocolate drink powder (26) reported in international GI tables (FosterPowell et al. 2002) are similar to those reported here.

Small differences of less than 10-15 units lie within the error associated with the measurement of GI (Wolever et al. 1991; Foster-Powell et al. 2002), but there were a few values that were notably different from those previously reported. In particular, the GI value of white bread reported in the current study was lower than that reported for most white breads. This may be due to differences in processing conditions and the use of new food ingredients in the baking 


\begin{tabular}{|c|c|c|c|c|c|c|c|}
\hline \multirow[b]{2}{*}{ Food } & \multirow{2}{*}{$\begin{array}{l}\text { Carbohydrate } \\
(\mathrm{g} / 100 \mathrm{~g})\end{array}$} & \multirow{2}{*}{$\begin{array}{l}\text { Experimental } \\
\text { portion }(\mathrm{g})\end{array}$} & \multicolumn{2}{|c|}{ GI } & \multirow{2}{*}{$\begin{array}{l}\text { Standard } \\
\text { serving size }(g)\end{array}$} & \multirow{2}{*}{$\begin{array}{l}\text { Carbohydrate } \\
\text { (g/serving) }\end{array}$} & \multirow{2}{*}{$\begin{array}{l}\text { GL (per } \\
\text { serving) }\end{array}$} \\
\hline & & & Mean & SE & & & \\
\hline \multicolumn{8}{|l|}{ Bread and crackers } \\
\hline Multiseed bread & $41 \cdot 8$ & $119 \cdot 6$ & 54 & 4 & 36 & $15 \cdot 0$ & $8 \cdot 1$ \\
\hline Seeded bread & $38 \cdot 2$ & $130 \cdot 9$ & 49 & 7 & 36 & $13 \cdot 8$ & $6 \cdot 8$ \\
\hline White bread & $44 \cdot 3$ & $112 \cdot 9$ & 59 & 11 & 46 & $20 \cdot 4$ & $12 \cdot 0$ \\
\hline White bread with wheatgerm and fibre & $41 \cdot 6$ & $120 \cdot 2$ & 49 & 12 & 33 & $13 \cdot 7$ & $6 \cdot 7$ \\
\hline Cheese-filled white rolls & 39.6 & $126 \cdot 3$ & 50 & 6 & 62 & $24 \cdot 6$ & $12 \cdot 3$ \\
\hline Choice grain crackers & 65.5 & $76 \cdot 3$ & 49 & 7 & 7 & 4.6 & $2 \cdot 3$ \\
\hline Rye crackers with oats & $63 \cdot 6$ & $78 \cdot 6$ & 64 & 11 & 13 & $8 \cdot 3$ & $5 \cdot 3$ \\
\hline Rye crackers with sesame & 64.9 & $77 \cdot 0$ & 57 & 12 & 13 & 8.4 & 4.8 \\
\hline Wholegrain crackers with sesame seeds and rosemary & $62 \cdot 3$ & $80 \cdot 3$ & 53 & 8 & 13 & $8 \cdot 1$ & $4 \cdot 3$ \\
\hline Wholewheat crackers with pumpkin and thyme & $61 \cdot 3$ & $81 \cdot 6$ & 36 & 3 & 13 & $8 \cdot 0$ & $2 \cdot 9$ \\
\hline Crunchy yeast-extract-flavoured wholewheat sticks & $57 \cdot 3$ & $87 \cdot 3$ & 50 & 8 & 25 & $14 \cdot 3$ & $7 \cdot 2$ \\
\hline \multicolumn{8}{|l|}{ Breakfast cereals } \\
\hline Cereal biscuit & $67 \cdot 1$ & 74.5 & 72 & 10 & 38 & $25 \cdot 5$ & $18 \cdot 4$ \\
\hline High-fibre cereal & $57 \cdot 4$ & $87 \cdot 1$ & 52 & 6 & 40 & $23 \cdot 0$ & $12 \cdot 0$ \\
\hline Hot oat cereal I (water) & $57 \cdot 4$ & $87 \cdot 1(348)$ & 83 & 10 & $30(120)$ & $17 \cdot 2$ & $14 \cdot 3$ \\
\hline \multicolumn{8}{|l|}{ Mixed meals - breakfast cereals } \\
\hline Cereal biscuit (semi-skimmed milk)* & $19 \cdot 1 \dagger$ & $60 \cdot 4(201]$ & 47 & 8 & 38 (125) & $31 \cdot 1$ & 14.6 \\
\hline Cereal biscuits - cocoa flavour (semi-skimmed milk) & $19 \cdot 4 \dagger$ & $57.7(200)$ & 46 & 7 & 36 (125) & $31 \cdot 2$ & 14.4 \\
\hline Cereal biscuits - honey flavour (semi-skimmed milk) & $19 \cdot 7 \dagger$ & $56 \cdot 8(197)$ & 52 & 7 & $36(125)$ & $31 \cdot 7$ & $16 \cdot 5$ \\
\hline Cereal biscuits - fruit flavour (semi-skimmed milk)* & $19 \cdot 0 \dagger$ & $58.9(204)$ & 56 & 7 & 36 (125) & $30 \cdot 6$ & $17 \cdot 1$ \\
\hline Cereal flakes with fruit (semi-skimmed milk)* & $21.9 \dagger$ & $55 \cdot 2(173)$ & 57 & 8 & 40 (125) & $36 \cdot 1$ & 20.6 \\
\hline Cocoa crunch cereal (semi-skimmed milk)* & $18 \cdot 2 \dagger$ & $53 \cdot 1(221)$ & 58 & 11 & 30 (125) & $28 \cdot 2$ & $16 \cdot 4$ \\
\hline Honey crunch cereal (semi-skimmed milk) ${ }^{\star}$ & $19.5 \dagger$ & $49 \cdot 6(207)$ & 54 & 6 & 30 (125) & $30 \cdot 2$ & $16 \cdot 3$ \\
\hline Hot oat cereal I (semi-skimmed milk) & $15 \cdot 3 \dagger$ & $65 \cdot 6(262)$ & 47 & 6 & 30 (120) & $23 \cdot 0$ & $10 \cdot 8$ \\
\hline Hot oat cereal II (semi-skimmed milk) ${ }^{\star}$ & $13 \cdot 6 \dagger$ & $61 \cdot 2(306)$ & 40 & 9 & $30(150)$ & 24.5 & $9 \cdot 8$ \\
\hline Hot oat cereal - berry flavour (semi-skimmed milk) & $19 \cdot 7 \dagger$ & $62 \cdot 0(192)$ & 43 & 6 & 40 (125) & 32.5 & $14 \cdot 0$ \\
\hline Hot oat cereal - cocoa flavour (semi-skimmed milk)* & $14.9 \dagger$ & $65.0(270)$ & 40 & 5 & 30 (125) & $23 \cdot 1$ & $9 \cdot 2$ \\
\hline Hot oat cereal - fruit flavour (semi-skimmed milk)* & $16 \cdot 0 \dagger$ & $60 \cdot 4(252)$ & 47 & 8 & 30 (125) & $24 \cdot 8$ & $11 \cdot 7$ \\
\hline Hot oat cereal - honey flavour (semi-skimmed milk) & $19.5 \dagger$ & $62 \cdot 0(194)$ & 47 & 6 & 40 (125) & $32 \cdot 2$ & $15 \cdot 1$ \\
\hline $\begin{array}{l}\text { Hot oat cereal - orchard fruit flavour } \\
(\text { semi-skimmed milk) }\end{array}$ & $18 \cdot 9 \dagger$ & $64 \cdot 0(200)$ & 50 & 7 & $40(125)$ & $31 \cdot 2$ & $15 \cdot 6$ \\
\hline \multicolumn{8}{|l|}{ Snack bars } \\
\hline Apricot and almond bar & 51.4 & $97 \cdot 3$ & 34 & 6 & 35 & $18 \cdot 0$ & $6 \cdot 1$ \\
\hline Cereal bar - cranberry flavour & 48.5 & $103 \cdot 1$ & 42 & 5 & 35 & $17 \cdot 0$ & $7 \cdot 1$ \\
\hline Cereal bar - hazelnut flavour & $36 \cdot 3$ & 137.7 & 33 & 6 & 35 & $12 \cdot 7$ & 4.2 \\
\hline Cereal bar - orange flavour & $47 \cdot 4$ & $105 \cdot 5$ & 33 & 3 & 35 & $16 \cdot 6$ & 5.5 \\
\hline \multicolumn{8}{|l|}{ Sweet biscuits } \\
\hline Digestive & $62 \cdot 7$ & $79 \cdot 7$ & 39 & 5 & 15 & 9.4 & 3.7 \\
\hline Rich Tea & $71 \cdot 2$ & $70 \cdot 2$ & 40 & 5 & 8 & $5 \cdot 7$ & $2 \cdot 3$ \\
\hline Oat biscuits & $60 \cdot 8$ & $82 \cdot 2$ & 45 & 7 & 14 & 8.5 & 3.8 \\
\hline \multicolumn{8}{|l|}{ Weight-management meals } \\
\hline Chocolate drink $\ddagger$ & $7 \cdot 0$ & $428 \cdot 6$ & 39 & 8 & 200 & $14 \cdot 0$ & 5.5 \\
\hline Chocolate flavour drink $\ddagger$ & $35 \cdot 3$ & $85 \cdot 0$ & 23 & 5 & 40 & $14 \cdot 1$ & $3 \cdot 2$ \\
\hline Chocolate soya drink $\ddagger$ & $54 \cdot 0$ & $55 \cdot 6$ & 73 & 17 & 53 & $28 \cdot 6$ & 20.9 \\
\hline Lactose-free chocolate drink $\ddagger$ & 38.0 & 78.9 & 29 & 10 & 40 & $15 \cdot 2$ & 4.4 \\
\hline Chicken and mushroom soup $\ddagger$ & 35.5 & 84.5 & 46 & 6 & 40 & $14 \cdot 2$ & 6.5 \\
\hline Chicken and mushroom soup $\ddagger$ & $37 \cdot 3$ & $80 \cdot 4$ & 69 & 14 & 40 & 14.9 & $10 \cdot 3$ \\
\hline
\end{tabular}


(A)

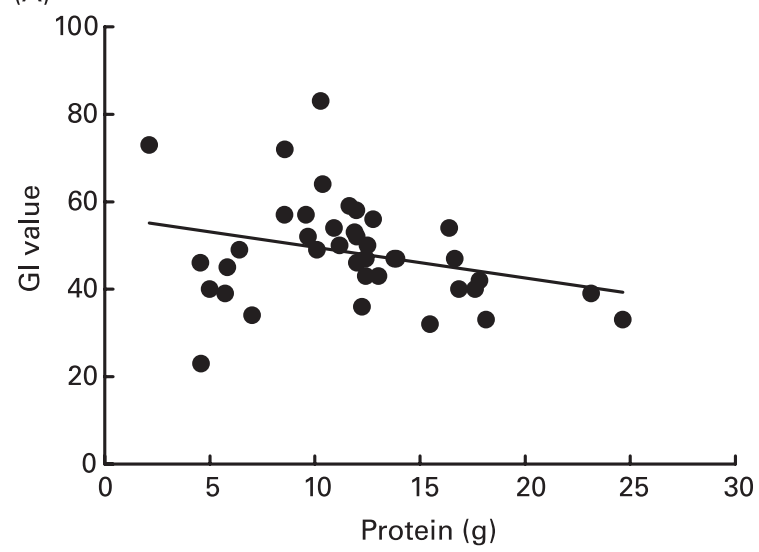

(B)

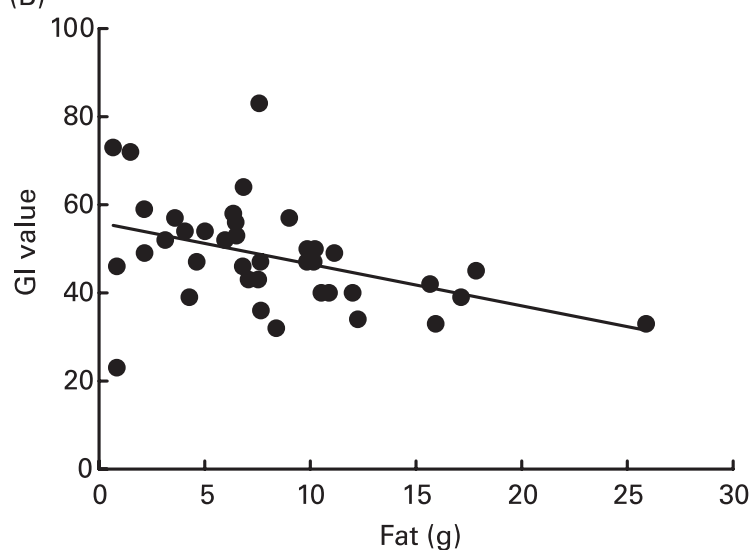

Fig. 2. Relationship between the glycaemic index (GI) value and the amount of protein (A) and fat (B) per $50 \mathrm{~g}$ available carbohydrate portion in all foods tested.

process. This therefore reconfirms the need to test food products in the country of consumption.

The weight-management meals were mostly low GI. There is considerable interest in the potential of low-GI foods for the management of obesity (Warren et al. 2003), and such products may play an important role in body-weight regulation. With the increasing consumption of weight-management meals in our society, the current GI table will enable consumers and researchers alike to select low-GI foods for their respective needs.

In the current study, 'mixed meal' testing of breakfast cereal with milk was conducted, in contrast to standard GI testing for breakfast cereals per se. Given the practical nature of GI, food companies, industry and individuals now want to know the GI values of food as eaten. The results from our study suggest that the addition of semi-skimmed milk to breakfast cereals may reduce the GI value. It is now well recognised that the low glycaemic response to milk does not solely depend on its lactose content. Milk protein has a strong insulinotropic effect (Nilsson et al. 2004). Consequently, when testing foods with the addition of milk, the role that milk proteins play may also need to be considered. Casein and whey proteins are rich sources of leucine and phenylalanine. Leucine in particular has been shown to promote insulin secretion by simulating $\beta$-cell function (van Loon et al. 2000). The results obtained from our study may be interpreted 

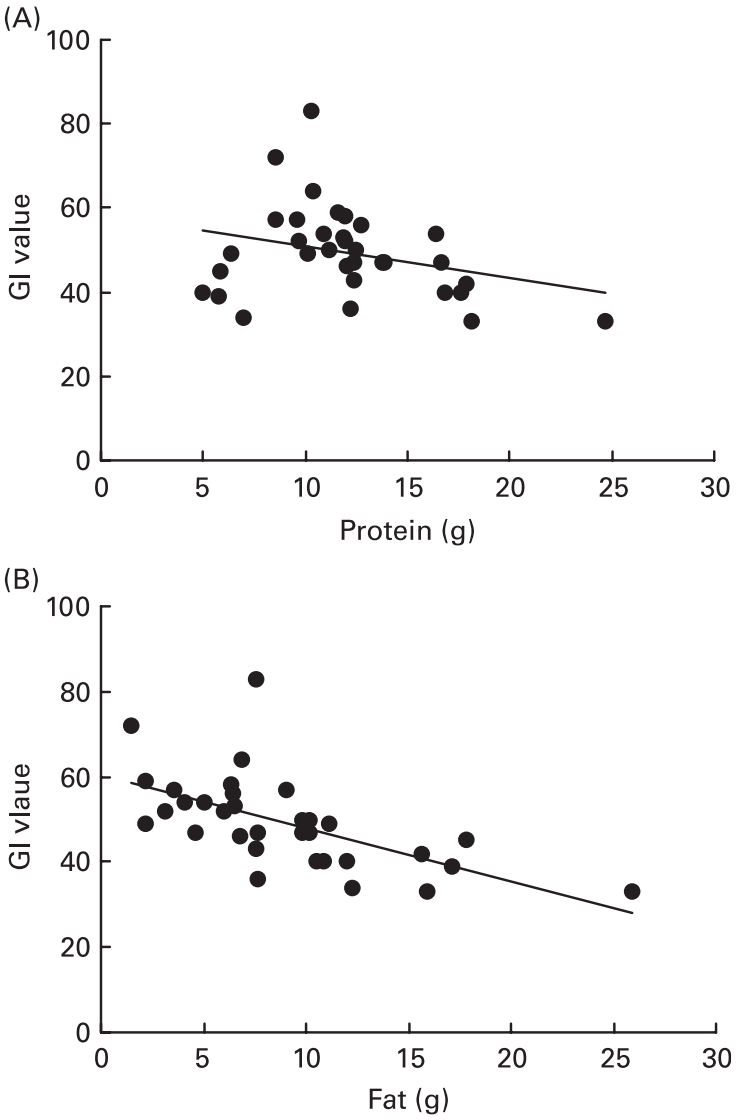

Fig. 3. Relationship between the glycaemic index (GI) value and the amount of protein (A) and fat (B) per $50 \mathrm{~g}$ available carbohydrate portion, excluding weight-management meals.

on the basis of the above observations. The co-ingested milk protein stimulated insulin production, which in turn facilitated glucose utilisation, leading to a lower GI value. Further investigations on the association between GI and lactose and fructose would be of interest.

The presence of large amounts of fat and protein may also reduce the GI of a food (Wolever et al. 1994). It is generally accepted that fat may lower the postprandial glucose response by delaying the rate of gastric emptying (Owen \& Wolever, 2003). It has also been speculated that lipids may bind with the amylose fraction of starch, rendering it less susceptible to amylase (Siswoyo \& Morita, 2001). Protein increases the amount of insulin secreted, causing blood glucose levels to be less affected, and may also form a protective network around the carbohydrate molecule, preventing the action of glycolytic enzymes (Bornet et al. 1987). In the present study, although an effect of protein and fat was not observed across the entire group of foods, there was a strong negative association with fat content when the weight-management meals (i.e. lower-fat foods) were excluded. Therefore, this does not rule out the fact that the GI value of individual products may be determined by their protein and fat content.

Many of the products presented in the current paper are a result of a simple reformulation and alteration of processing conditions by food manufacturers to reduce the glycaemic response of the food; for example, a reformulated white bread in our study had a GI value of 59 compared with a GI value of 70 for standard white wheat flour bread (FosterPowell et al. 2002). This confirms the view that the demand for and interest in low-GI foods is an adequate stimulus for the food industry to develop such foods.

In conclusion, the present paper provides reliable GI and GL values for a range of different foods and mixed meals consumed in the UK, further advancing our understanding of the glycaemic response of different foods. The data reported here make an important addition to published GI values, enabling consumers to have a wider range and selection of low-GI foods to choose from.

\section{Acknowledgements}

We thank the following food companies for their contribution: British Bakels Ltd, Cambridge Manufacturing Company Limited, CSM Bakery Supplies Europe, Lyme Regis Fine Foods Ltd, United Biscuits and Warburtons Ltd.

\section{References}

Augustin LS, Franceschi S, Jenkins DJA, Kendall CWC \& La Vecchia C (2002) Glycemic index in chronic disease: a review. Eur J Clin Nutr 56, 1049-1071.

Björck I, Granfeldt Y, Liljeberg H, Tovar J \& Asp NG (1994) Food properties affecting the digestion and absorption of carbohydrates. Am J Clin Nutr 59, S699-S705.

Bland JM \& Altman DG (1986) Statistical methods for assessing agreement between two methods of clinical measurement. Lancet I, 307-310.

Bornet FRJ, Costagliola D, Rizkalla SW, Blayo A, Fontvieille A, Haardt M, Letanoux M, Tchobroutsky G \& Slama G (1987) Insulinemic and glycemic indexes of six starch-rich foods taken alone and in a mixed meal by type 2 diabetics. Am J Clin Nutr 45, $588-595$.

Brand-Miller J, Foster-Powell K \& Colagiuri S (2003) The New Glucose Revolution. New York: Marlowe.

Brouns F, Bjorck I, Frayn KN, Gibbs AL, Lang V, Slama G \& Wolever TMS (2005) Glycaemic index methodology. Nutr Res Rev 18, 145-171.

FAO/WHO (1998) Carbohydrates in Human Nutrition. Report of a Joint FAO/WHO Expert Consultation. Rome: FAO.

Food Standards Agency (2004) Food Portion Sixes, 3rd ed. London: TSO.

Foster-Powell K, Holt SHA \& Brand-Miller JC (2002) International table of glycemic index and glycaemic load values: 2002. Am J Clin Nutr 76, 5-56.

Frost G, Leeds AA, Dore CJ, Madeiros S, Brading S \& Dornhorst A (1999) Glycaemic index as a determinant of serum HDL-cholesterol concentration. Lancet 353, 1045-1048.

Henry CJK, Lightowler HJ, Strik CM, Renton H \& Hails S (2005) Glycaemic index and glycaemic load values of commercially available products in the United Kingdom. Br J Nutr 94, 922-930.

Jenkins DJA, Wolever TMS, Taylor RH, Barker H, Fielden H, Baldwin JM, Bowling AC, Newman HC, Jenkins AL \& Goff DV (1981) Glycemic index of foods: a physiological basis for carbohydrate exchange. Am J Clin Nutr 34, 362-366.

Ludwig DS (2000) Dietary glycemic index and obesity. J Nutr 130, 280S-283S.

Nilsson M, Stenberg M, Frid AH, Holst JJ \& Björck IME (2004) Glycemia and insulinemia in healthy subjects after lactoseequivalent meals of milk and other food proteins: the role of 
plasma amino acids and incretins. Am J Clin Nutr 80, $1246-1253$.

Owen B \& Wolever TMS (2003) Effect of fat on glycaemic response in normal subjects: a dose-response study. Nutr Res 23, $1341-1347$.

Salmeron J, Ascherio A, Rimm EB, Colditz GA, Spiegelman D, Jenkins DJ, Stampfer MJ, Wing AL \& Willet EC (1997a) Dietary fiber, glycaemic load, and risk of NIDDM in men. Diabetes Care 20, 545-550.

Salmeron J, Manson JE, Stampfer MJ, Colditz GA, Wing AL \& Willet EC (1997b) Dietary fiber, glycaemic load, and risk of non-insulindependent diabetes mellitus in women. JAMA 277, 472-477.

Siswoyo TA \& Morita N (2001) Influence of acyl chain lengths in mono- and diacyl-sn-glycerophosphatidylcholine on gelatinization and retrogradation of starch. J Agric Food Chem 49, 4688-4693.

van Loon LJ, Saris WH, Verhagen H \& Wagenmakers AJ (2000) Plasma insulin responses after ingestion of different amino acid or protein mixtures with carbohydrate. Am J Clin Nutr 72, 96-105.

Warren JM, Henry CJK \& Simonite V (2003) Low glycaemic index breakfasts and reduced food intake in preadolescent children. Pediatrics 112, E414-E419.

Wolever TMS, Jenkins DJA, Jenkins AL \& Josse RG (1991) The glycemic index: methodology and clinical implications. Am J Clin Nutr 54, 846-854.

Wolever TMS, Katzmanrelle L, Jenkins AL, Vuksan V, Josse RG \& Jenkins DJA (1994) Glycemic index of 102 complex carbohydrate foods in patients with diabetes. Nutr Res 14, 651-669. 